\title{
Pengaruh Akuntabilitas Keuangan Daerah, Value For Money, Kejujuran, Transparansi, Dan Pengawasan Terhadap Pengelolaan Keuangan Daerah (Studi Kajian Pada Pemerintah Kabupaten Labuhanbatu Pusat)
}

\author{
Fredo TSP Hasugian ${ }^{1}$, Ricky Ary Syahputra ${ }^{2}$, Aulia Rahman Harahap ${ }^{2 *}$ \\ ${ }^{1}$ Politeknik Unggul LP3M, Medan \\ ${ }^{2}$ Satuan Audit Internal, Universitas Sumatera Utara \\ E-mail: *2aulia.harahap@usu.ac.id
}

\begin{abstract}
This study aims to examine the influence of local financial accountability, value for money, honesty, transparency and supervision of local financial management. The sample of this research is all SKPD (Local Work Unit Unit) as user of budget related to regional finance management at Regency Government of Labuhanbatu amounting 36 SKPD and 36 Committing Officer of Commitment so amounted 72 person. Sampling method is census method, and data used is primary data. Data were collected by distributing the queryer directly submitted to the respondent. Data analysis techniques use path analysis with the help of SmartPLS 3 program.

The results of this study show that value for money, honesty, transparency and oversight have positive and significant correlation to Regional Financial Management, while Regional Financial Accountability has negative and significant correlation to Regional Financial Management.
\end{abstract}

Keywords: Accountability, Value for money, honesty, transparency,oversight and financial management

\begin{abstract}
Abstrak
Penelitian ini bertujuan untuk menguji pengaruh akuntabilitas keuangan daerah, value for money, kejujuran, transparansi dan pengawasan terhadap pengelolaan keuangan daerah. Sampel penelitian ini adalah seluruh SKPD (Satuan Kerja Perangkat Daerah) sebagai pengguna anggaran yang terkait dengan pengelolaan keuangan daerah pada Pemerintah Kabupaten Labuhanbatu yang berjumlah 36 SKPD dan 36 Pejabat Pembuat Komitmen sehingga berjumlah 72 orang. Metode pengambilan sampel adalah metode sensus, dan data yang digunakan adalah data primer. Pengumpulan data dilakukan dengan cara menyebarkan kueri yang langsung disampaikan kepada responden. Teknik analisis data menggunakan analisis jalur dengan bantuan program SmartPLS 3.

Hasil penelitian ini menunjukkan bahwa value for money, kejujuran, transparansi dan pengawasan memiliki hubungan positif dan signifikan terhadap Pengelolaan Keuangan Daerah, sedangkan Akuntabilitas Keuangan Daerah memiliki hubungan negatif dan signifikan terhadap Pengelolaan Keuangan Daerah.
\end{abstract}

Kata kunci: Akuntabilitas, Nilai uang, kejujuran, transparansi, pengawasan dan pengelolaan keuangan financial

doi: https://doi.org/10.51544/jma.v6i2.1997

(C) 2021 Jurnal Mutiara Akuntansi. This is an open access article under the CC BY-SA licenseWebsite: http://e-journal.sari-mutiara.ac.id/index.php/JMA/ 


\section{PENDAHULUAN}

Dalam rangka menciptakan tata kelola pemerintahan yang baik (Good Governance), pemerintah Indonesia terus melakukan berbagai usaha untuk meningkatkan transparansi dan akuntabilitas pengelolaan keuangan negara, salah satunya adalah dengan melakukan pengembangan kebijakan akuntansi pemerintah berupa Standar Akuntansi Pemerintahan (SAP) yang bertujuan memberikan pedoman pokok dalam penyusunan dan penyajian Laporan Keuangan baik di Pemerintah Pusat maupun di Pemerintah Daerah. Pemerintah daerah otonom memiliki kewenangan untuk melakukan pengelolaan semua sektor pembangunan yang berada di wilayah kabupaten / kota tersebut. Hal ini sesuai dengan amanat dari Peraturan Pemerintah nomor 25 tahun 2000.

Selanjutnya, untuk menjalankan roda pembangunan didaerah tersebut maka dibentuklah Satuan Perangkat Kerja Daerah (SKPD) dengan mengacu kepada tiga fungsi pemerintahan daerah yaitu melakukan tugas pemerintahan, tugas pembangunan dan tugas pelayanan masyarakat. Dalam pelaksanaan fungsi fungsi diatas pemeritah daerah memberdayakan berbagai sumber dana baik yang berasal dari Pendapatan Asli Daerah, Dana Alokasi Umum, dana alokasi khusus, dana dekonsentrasi maupun dana bagi hasil.

Selanjutnya berkaitan dengan pengelolaan keuangan daerah khususnya dalam hal pengendalian, dapat dilihat dari seberapa besar SKPD (Satuan Kerja Perangkat Daerah) mampu melaksanakan elemen - elemen manajemen keuangan daerahyang diperlukan meliputi akuntabilitas keuangan daerah, value for money, kejujuran, transparansi dan pengawasan. Lima variabel ini dapat dijadikan ukuran terhadap keberhasilan pemerintah daerah dalam mengelola keuangan daerah.

Mengingat demikian kompleksnya pengelolaan keuangan daerah disamping sumberdaya manusianya yang relatif terbatas bila diukur dari aspek kualitas maka penulis berminat untuk melakukan kajian dan analisis terhadap variabel - variabel yang menjadi tolak ukur pengelolaan keuangan daerah meliputi Akuntabilitas Keuangan Daerah, Value for Money, Kejujuran, Transparansi dan Pengawasan, dengan melakukan studi kajian pada Pemerintah kabupaten labuhan batu - Provinsi Sumatera Utara. Dengan adanya kajian ini diharapkan akan dapat meningkatkan kinerja dan responsibilitas seluruh perangkat SKPD Pemerintah Kabupaten/Kota maupun Pemerintah Provinsi untuk melakukan pengelolaan keuangan daerah yang baik sehinggapada akhirnya akan meningkatkan efektifitas dan efisiensi penggunaan anggaran dalam rangka peningkatan kesejahteraan dan pelayanan kepada masyarakat.

\section{TINJAUAN PUSTAKA Keuangan Daerah}

Keuangan Daerah tidak terlepas dan selalu terkait dengan anggaran pendapatan dan belanja daerah (APBD), karena keuangan daerah tersebut telah ditetapkan dalam APBD (Nordiawan, 2007).

Sesuai Peraturan Menteri Dalam Negeri (Permendagri) Nomor 13 Tahun 2006, tentang Pedoman Pengelolaan Keuangan Daerah, pasal 311, menyebutkan bahwa (1)DPRD melakukan pengawasan terhadap pelaksanaan peraturan daerah (Perda) tentangAPBD, (2) Pengawasan sebagaimana dimaksud pada ayat (1) bukan pemeriksaan tetapi pengawasan yang lebih mengarah untuk menjamin pencapaian sasaran yang telah ditetapkan dalam peraturan daerah tentang APBD, dan pasal 312 menyebutkan Pengawasan pengelolaan keuangan daerah berpedoman pada ketentuan peraturan perundang - undangan.

\section{Anggaran Pendapatan dan Belanja Daerah (APBD)}

Menurut Renyowijoyo (2008 : 98) "fungsi anggaran adalah: (1) sebagai pedoman pemerintah dalam mengelola Negara pada periode mendatang, (2) alat pengawas bagi masyarakat terhadap kebijakan pemerintah, (3) dan alat pengawas terhadap kemampuan pelaksanaan kebijakan pemerintah". 
Menurut Mardiasmo (2002:70), prinsip -prinsip pokok siklus anggaran perlu diketahui dengan baik oleh penyelenggara pemerintah. Pada dasarnya prinsip -prinsip dan mekanisme penganggaran relatif tidak berbeda antara sektor swasta dengan sektor publik.

\section{Pejabat Pengguna Anggaran dan Barang}

Peraturan Pemerintah Dalam Negeri (Permendagri) Nomor 13 tahun 2006 yang diubah menjadi Peraturan Pemerintah No.58 tahun 2007 bahwa pejabat pengguna anggaran/pengguna barang terdiri dari: (1) Kepala SKPD, (2) Pejabat kuasa pengguna anggaran/kuasa pengguna barang, (3) Pejabat pelaksana teknis kegiatan SKPD, (4) Pejabat penatausahaan Keuangan SKPD (5) Bendahara Penerimaan Bendahara Pengeluaran.

\section{Pemerintahan yang Baik (Good Governance)}

Pemerintahan yang baik (Good Governance), adalah suatu kesuksesan pemerintah dalam mengelola keuangan untuk pelayanan umum (sektor public) dengan baik.

United Nation Development Program menyebutkan enam indikator kesuksesan good governance yaitu :

(1) Mengikut sertakan semua, (2) transparan dan bertanggungjawab, (3) efektif dan adil, (4) menjamin adanya supremasi hukum, (5) menjamin bahwa prioritas - prioritas politik, sosial, ekonomi didasarkan pada konsensus masyarakat, (6) memperhatikan kepentingan mereka yang paling miskindan lemah dalam proses mengambil keputusan menyangkut alokasi sumber daya pembangunan.

\section{Akuntabilitas Keuangan Daerah}

Akuntabilitas keuangan daerah adalah kewajiban pemerintah daerah untuk memberikan pertanggungjawaban, menyajikan, melaporkan, dan mengungkapkan segala akfivitas dan kegiatan yang terkait dengan penerimaan dan penggunaan uang publik kepada pihak yang memiliki hak dan kewenangan untuk meminta pertanggungjawaban tersebut (DPRD dan masyarakat luas).

\section{Value For Money}

"Value For Money (VFM) merupakan konsep pengelolaan organisasi sektor publik yang mendasarkan pada tiga jenis elemen yaitu : ekonomi, efisiensi, dan efektifitas".

\section{Kejujuran}

Kejujuran atau fairness merupakan bagian dari tujuan "goodgovernance" yaitu hal wajib yang harus dilaksanakan oleh pemerintah daerah untuk menunjang terlaksananya pemerintahan yang bersih dari Kolusi, Korupsi dan Nepotisme (KKN), dan salahsatunya pemerintah daerah selama ini dengan tegas melaksanakan akuntablitas kejujuran (Accountability for probit) terkait dengan penghindaran penyalahgunaan jabatan (abuse of power) dengan memberikan funishment (hukuman) kepada setiap aparatur pemerintah yang melanggarnya.

\section{Transparansi}

"Transparansi adalah memberikan informasi keuangan yang terbuka dan jujur kepada masyarakat berdasarkan pertimbangan bahwa masyarakat memiliki hakuntuk mengetahui secara terbuka dan menyeluruh atas pertanggungjawaban pemerintahan dalam pengelolaan sumber daya yang dipercayakan kepadanya dan ketaatannya pada peraturan perundang-undangan". Erlina, Sirojuzilam, Rasdianto (2012 : 42).

\section{Pengawasan}

Menurut Keputusan Presiden (Kepres) No. 74 tahun 2001 tentang tata cara pengawasan penyelenggaraan pemerintah daerah, pasal 1 ayat 6 menyebutkan bahwa pengawasan pemerintah daerah adalah proses kegiatan yang ditujukan untuk menjamin agar pemerintah daerah berjalan sesuai dengan rencana ketentuan peraturan perundang - undangan yang berlaku. 


\section{Pengelolan Keuangan Daerah}

Pengelolaan keuangan daerah adalah keseluruhan kegiatan yang meliputi perencanaan, pelaksanaan, penatausahaan, pelaporan, pertanggung- jawaban, dan pengawasan keuangan daerah (Permendagri No.13 tahun 2006). Keuangan daerah dikelola secara tertib, taat pada peraturan perundang - undangan, efektif, efisien, ekonomis, transparan, dan bertanggungjawab dengan memperhatikan azas keadilan, kepatutan dan manfaat untuk masyarakat. Kepala daerah selaku pemegang kekuasaan pengelolaan keuangan daerah melimpahkan sebagian atau seluruh kekuasaannya kepada (a) sekretaris daerah selaku kordinator pengelola keuangan daerah, (b) kepala SKPKD selaku PPKD, (c) kepala SKPD selaku pejabat pengguna anggaran/pengguna barang.

Berdasarkan tinjauan pustaka (teori), maka hipotesis penelitian ini adalah :

$\mathrm{H}_{1}$ : Akuntabilitas keuangan daerah berpengaruh terhadap pengelolaan keuangan daerah di pemerintahan kabupaten Labuhanbatu Pusat.

$\mathrm{H}_{2}$ : Value for money berpengaruh terhadap pengelolaan keuangan daerah pada pemeritahan Kabupaten Labuhanbatu Pusat.

$\mathrm{H}_{3}$ : Tingkat kejujuran pegawai berpengaruh terhadap pengelolaan keuangan pada pemerintahan Kabupaten Labuhanbatu Pusat.

$\mathrm{H}_{4}$ : Transparansi berpengaruh terhadap pengelolaan keuangan pada Pemerintahan kabupaten Labuhanbatu Pusat.

$\mathrm{H}_{5}$ : Pengawasan berpengaruh terhadap pengelolaan keuangan daerah pada pemerintahan Kabupaten Labuhanbatu Pusat.

\section{METODE PENELITIAN}

Jenis penelitian ini dapat dikatakan sebagai penelitian kausal yaitu untuk melihat hubungan beberapa variabel yang belum pasti, Umar (2008). Peneliti menggunakan penelitian ini untuk memberikan bukti empiris dari analisis pengaruh akuntabilitas keuangan daerah, value for money, kejujuran, transparansi, dan pengawasan terhadap pengelolaan keuangan daerah. Penelitian ini dilakukan pada seluruh SKPD Pemerintah Kabupaten Labuhanbatu Pusat, Provinsi Sumatera Utara, rencana waktu penelitian yakni 6 minggu (Agustus s/d September 2017). Jumlah SKPD di lingkungan Pemerintahan Kabupaten Labuhanbatu Pusat sebanyak 36 SKPD, dan seluruhnya disebarkan kuisioner.

Ruang lingkup pada penelitian ini dibatasi pada 5 variabel eksogen (X) yang diperkirakan berpengaruh terhadap pengelolaan keuangan daerah (Y) yaitu akuntabilitas keuangan daerah $\left(\mathrm{X}_{1}\right)$, value for money $\left(\mathrm{X}_{2}\right)$, kejujuran $\left(\mathrm{X}_{3}\right)$, transparansi $\left(\mathrm{X}_{4}\right)$, dan pengawasan $\left(\mathrm{X}_{5}\right)$.

Masing - masing variabel diukur dengan model Skala Likert yaitu mengukur sikap dengan menyatakan setuju atau ketidak setujuannya terhadap pertanyaan yang diajukan dengan skor sebagai berikut :

$$
\begin{aligned}
& 5=(\text { SS }=\text { Sangat Setuju }) \\
& 4=(\mathrm{S}=\text { Setuju }) \\
& 3=(\mathrm{TT}=\text { Tidak Tahu }) \\
& 2=(\mathrm{TS}=\text { Tidak Setuju }) \\
& 1=(\text { STS }=\text { Sangat Tidak Setuju })
\end{aligned}
$$

Populasi dalam penelitian ini adalah pejabat/aparatur Pemerintah Kabupaten Labuhanbatu Pusat yang terlibat langsung dalam pengelolaan keuangan daerah yaitu kepala dan seluruh Pejabat Pembuat Komitmen (PPK) disetiap SKPD dan Pejabat Pelaksana Teknis Kegiatan (PPTK), namun yang menjadi sampel hanya Kepala SKPD dan seorang Pejabat Pembuat Komitmen. Dengan demikian yang menjadi sampel dalam penelitian ini sebanyak 72 orang. Jenis data yang dipergunakan dalam penelitian ini 
adalah data primer yang diperoleh melalui alat pengumpul data berupa kuisioner yang diedarkan secara langsung. Kuisioner ini berisi berbagai pertanyaan dan pernyataan yang berkaitan dengan variabel - variabel yang akan diteliti.

Sumber data penelitian ini merupakan faktor penting yang menjadi pertimbangan dalam penentuan metode pengumpulan data. Penelitian ini menggunakan data primer. Untuk mendapatkan data dari responden digunakan instrumen penelitian berupa kuisioner yang diantar langsung oleh penulis dalam satu tahap yaitu kuisioner diantara langsung oleh peneliti kepada responden sebanyak 72 kuisioner, dan responden diberi waktu untuk menjawab pertanyaan kuisioner hingga7 (tujuh) hari setelah kuisioner diberikan.

Kuisioner dalam penelitian ini peneliti adopsi dari Penelitian Liper Siregar (2011), dan sebagian kuisioner peneliti tambah atau kurangi sesuai judul yang peneliti ambil dengan sumber referensi sebagai berikut : Nordiawan. Deddi, Iswahyudi Sondi Putra,Mulidah Rahmawati (2007) dalam bukunya Akuntansi Pemerintahan. Jakarta; Mursyidi (2009), Akuntansi Pemerintahan di Indonesia, Refika Aditama Bandung;Mardiasmo (2002), Otonomi dan Manajemen Keuangan Daerah, Jogjakarta; Peraturan Menteri Dalam Negeri No. 13 tahun (2006), Tentang Pedoman Pengelolaan Keuangan Daerah; Sulistioni, G. (2003), Fiqh Korupsi : Amanah VS Kekuasaan, Somasi, Nusa Tenggara Barat.

Analisis data dalam penelitian ini menggunakan pendekatan Partial Least Square (PLS). PLS adalah model persamaan Structural Equation Modeling (SEM) yang berbasis komponen atau varian.

\section{HASIL DAN ANALISIS}

\section{Menilai Outer Model atau Measurement Model}

Tabel 4.6

Outer Loadings (Measurement Model)

\begin{tabular}{|c|c|c|}
\hline & Model Awal & Modifikasi \\
\hline & \multicolumn{2}{|c|}{ Akuntabilitas Keuangan Daerah $\left(\mathbf{X}_{1}\right)$} \\
\hline X1Q1 & $-0,317$ & \\
\hline $\mathrm{X} 1 \mathrm{Q2}$ & 0,080 & \\
\hline X1Q3 & 0,397 & \\
\hline X1Q4 & 0,641 & 0,702 \\
\hline X1Q5 & 0,668 & 0,784 \\
\hline X1Q6 & 0,635 & 0,772 \\
\hline X1Q7 & 0,574 & 0,661 \\
\hline \multirow[t]{3}{*}{ X1Q8 } & 0,693 & 0,710 \\
\hline & Model Awal & Modifikasi \\
\hline & \multicolumn{2}{|c|}{ Value for Money $\left(\mathrm{X}_{2}\right)$} \\
\hline X2Q1 & 0,798 & 0,803 \\
\hline $\mathrm{X} 2 \mathrm{Q} 2$ & 0,766 & 0,804 \\
\hline X2Q3 & 0,762 & 0,818 \\
\hline X2Q4 & 0,670 & 0,604 \\
\hline X2Q5 & 0,374 & \\
\hline X2Q6 & 0,356 & \\
\hline X2Q7 & 0,289 & \\
\hline \multirow{3}{*}{$\mathrm{X} 2 \mathrm{Q8}$} & 0,092 & \\
\hline & Model Awal & Modifikasi \\
\hline & \multicolumn{2}{|c|}{ Kejujuran $\left(\mathbf{X}_{3}\right)$} \\
\hline X3Q1 & 0,746 & 0,789 \\
\hline X3Q2 & 0,689 & 0,734 \\
\hline
\end{tabular}


Fredo TSP Hasugian / Jurnal Mutiara Akuntansi Vol. 6, No. 2 (Desember 2021) 174-

\begin{tabular}{|c|c|c|}
\hline X3Q3 & 0,728 & 0,765 \\
\hline X3Q4 & 0,868 & 0,892 \\
\hline X3Q5 & 0,785 & 0,785 \\
\hline X3Q6 & 0,680 & 0,599 \\
\hline X3Q7 & 0,357 & \\
\hline \multirow[t]{3}{*}{ X3Q8 } & 0,135 & \\
\hline & Model Awal & Modifikasi \\
\hline & \multicolumn{2}{|c|}{ Transparansi $\left(\mathrm{X}_{4}\right)$} \\
\hline X4Q1 & 0,683 & 0,660 \\
\hline $\mathrm{X} 4 \mathrm{Q} 2$ & 0,844 & 0,869 \\
\hline X4Q3 & 0,750 & 0,797 \\
\hline X4Q4 & 0,585 & 0,602 \\
\hline X4Q5 & 0,241 & \\
\hline X4Q6 & 0,290 & \\
\hline X4Q7 & 0,251 & \\
\hline X4Q8 & 0,258 & \\
\hline X4Q9 & 0,202 & \\
\hline \multirow[t]{3}{*}{ X4Q10 } & 0,205 & \\
\hline & Model Awal & Modifikasi \\
\hline & \multicolumn{2}{|c|}{ Pengawasan $\left(X_{5}\right)$} \\
\hline X5Q1 & 0,063 & \\
\hline X5Q2 & $-0,001$ & \\
\hline X5Q3 & $-0,183$ & \\
\hline X5Q4 & 0,010 & \\
\hline X5Q5 & 0,403 & \\
\hline X5Q6 & 0,724 & 0,766 \\
\hline X5Q7 & 0,842 & 0,895 \\
\hline X5Q8 & 0,842 & 0,892 \\
\hline \multirow[t]{3}{*}{ X5Q9 } & 0,481 & \\
\hline & Model Awal & Modifikasi \\
\hline & \multicolumn{2}{|c|}{ Pengelolaan Keuangan Daerah (Y) } \\
\hline YQ1 & 0,648 & 0,668 \\
\hline YQ2 & 0,738 & 0,755 \\
\hline YQ3 & 0,732 & 0,750 \\
\hline YQ4 & 0,627 & 0,612 \\
\hline YQ5 & 0,842 & 0,828 \\
\hline YQ6 & 0,789 & 0,777 \\
\hline YQ7 & 0,743 & 0,727 \\
\hline YQ8 & 0,751 & 0,737 \\
\hline
\end{tabular}

\section{Statistik Deskriptif}

Tabel 4.7

Statistik Deskriptif

Descriptive Statistics

\begin{tabular}{|c|c|c|c|c|c|}
\hline & $\mathrm{N}$ & Minimum & Maximum & Mean & Std. Deviation \\
\hline X1 & 72 & 17 & 25 & 21,3611 & 1,93052 \\
X2 & 72 & 13 & 20 & 17,5556 & 1,76738 \\
X3 & 72 & 23 & 30 & 28,9583 & 1,83424 \\
X4 & 72 & 12 & 20 & 17,6528 & 1,82440 \\
X5 & 72 & 9 & 15 & 12,0417 & 1,20372 \\
Y & 72 & 28 & 40 & 35,0417 & 3,03240 \\
Valid N & 72 & & & & \\
(listwise) & & & & & \\
\hline
\end{tabular}

http://e-journal.sari-mutiara.ac.id 
Fredo TSP Hasugian / Jurnal Mutiara Akuntansi Vol. 6, No. 2 (Desember 2021) 175-185

Discriminant Validity

Tabel 4.8

Nilai Discriminant validity (Cross loading)

\begin{tabular}{|c|c|c|c|c|c|c|}
\hline & $\mathrm{X1}$ & $\mathrm{X} 2$ & $\mathbf{X 3}$ & X4 & $\mathrm{X5}$ & $\mathbf{Y}$ \\
\hline X1Q4 & 0,702 & $-0,172$ & 0,035 & 0,182 & $-0,057$ & $-0,211$ \\
\hline X1Q5 & $\mathbf{0 , 7 8 4}$ & $-0,118$ & 0,331 & 0,101 & 0,023 & $-0,130$ \\
\hline X1Q6 & 0,772 & $-0,061$ & 0,219 & 0,165 & 0,006 & $-0,076$ \\
\hline X1Q7 & 0,661 & 0,186 & 0,259 & 0,361 & 0,183 & $-0,082$ \\
\hline X1Q8 & 0,710 & 0,051 & -0.068 & 0,127 & 0,114 & $-0,196$ \\
\hline X2Q1 & $-0,037$ & $\mathbf{0 , 8 0 3}$ & 0,274 & 0,269 & 0,191 & 0,443 \\
\hline $\mathrm{X} 2 \mathrm{Q} 2$ & $-0,236$ & $\mathbf{0 , 8 0 4}$ & 0,200 & 0,145 & 0,063 & 0,311 \\
\hline X2Q3 & 0,001 & 0,818 & 0,171 & 0,223 & 0,004 & 0,389 \\
\hline X2Q4 & 0,116 & 0,604 & 0,452 & 0,318 & 0,085 & 0,210 \\
\hline X3Q1 & 0,062 & 0,253 & 0,789 & 0,186 & 0,135 & 0,376 \\
\hline X3Q2 & 0,143 & 0,219 & 0,734 & 0,328 & 0,218 & 0,301 \\
\hline X3Q3 & 0,096 & 0,089 & 0,765 & $-0,092$ & 0,254 & 0,286 \\
\hline X3Q4 & 0,151 & 0,328 & 0,892 & 0,139 & 0,142 & 0,322 \\
\hline X3Q5 & 0,117 & 0,255 & 0,785 & $-0,204$ & 0,233 & 0,244 \\
\hline X3Q6 & 0,132 & 0,382 & 0,599 & 0,003 & 0,195 & 0,243 \\
\hline X4Q1 & 0,370 & 0,054 & 0,066 & 0,660 & 0,048 & 0,255 \\
\hline X4Q2 & 0,151 & 0,252 & 0,108 & 0,869 & 0,038 & 0,282 \\
\hline $\mathrm{X} 4 \mathrm{Q3}$ & 0,190 & 0,348 & 0,182 & 0,797 & 0,084 & 0,238 \\
\hline X4Q4 & 0,000 & 0,226 & $-0,065$ & 0,602 & 0,001 & 0,234 \\
\hline X5Q6 & 0,033 & 0,066 & 0,135 & 0,014 & 0,766 & 0,196 \\
\hline X5Q7 & 0,144 & $-0,023$ & 0,093 & 0,088 & 0,895 & 0,240 \\
\hline X5Q8 & $-0,002$ & 0,198 & 0,334 & 0,043 & $\mathbf{0 , 8 9 2}$ & 0,380 \\
\hline YQ1 & $-0,100$ & 0,486 & 0,391 & 0,351 & 0,101 & 0,688 \\
\hline YQ2 & $-0,204$ & 0,427 & 0,292 & 0,334 & 0,255 & 0,755 \\
\hline YQ3 & $-0,197$ & 0,488 & 0,314 & 0,344 & 0,264 & $\mathbf{0 , 7 5 0}$ \\
\hline YQ4 & $-0,288$ & 0,154 & 0,152 & 0,000 & 0,263 & 0,612 \\
\hline YQ5 & $-0,256$ & 0,281 & 0,317 & 0,176 & 0,271 & 0,828 \\
\hline YQ6 & $-0,057$ & 0,351 & 0,268 & 0,267 & 0,231 & 0,777 \\
\hline YQ7 & $-0,094$ & 0,190 & 0,268 & 0,200 & 0,356 & 0,727 \\
\hline YQ8 & $-0,118$ & 0,189 & 0,247 & 0,143 & 0,354 & $\mathbf{0 , 7 3 7}$ \\
\hline
\end{tabular}

Sumber: Pengolahan data dengan SmartPLS, 2017

Mengevaluasi Reliability dan Average Variance Extracted (AVE)

Tabel 4.9

Nilai Composite Reliability dan Average Variance Extracted (AVE)

\begin{tabular}{|l|c|c|}
\hline \multicolumn{1}{|c|}{ Variabel } & $\begin{array}{c}\text { Composite } \\
\text { Reliability }\end{array}$ & $\begin{array}{c}\text { Average Variance } \\
\text { Extracted (AVE) }\end{array}$ \\
\hline Akuntabilitas Keuangan & 0,848 & 0,529 \\
\hline Value for Money & 0,846 & 0,581 \\
\hline Kejujuran & 0,893 & 0,586 \\
\hline Transparansi & 0,826 & 0,547 \\
\hline Pengawasan & 0,889 & 0,728 \\
\hline Pengelolaan Keuangan Daerah & 0,903 & 0,539 \\
\hline
\end{tabular}

Sumber: Pengolahan data dengan SmartPLS, 2017 


\section{Pengujian Model Struktural (Inner Model)}

Gambar 4.1

Model Struktural

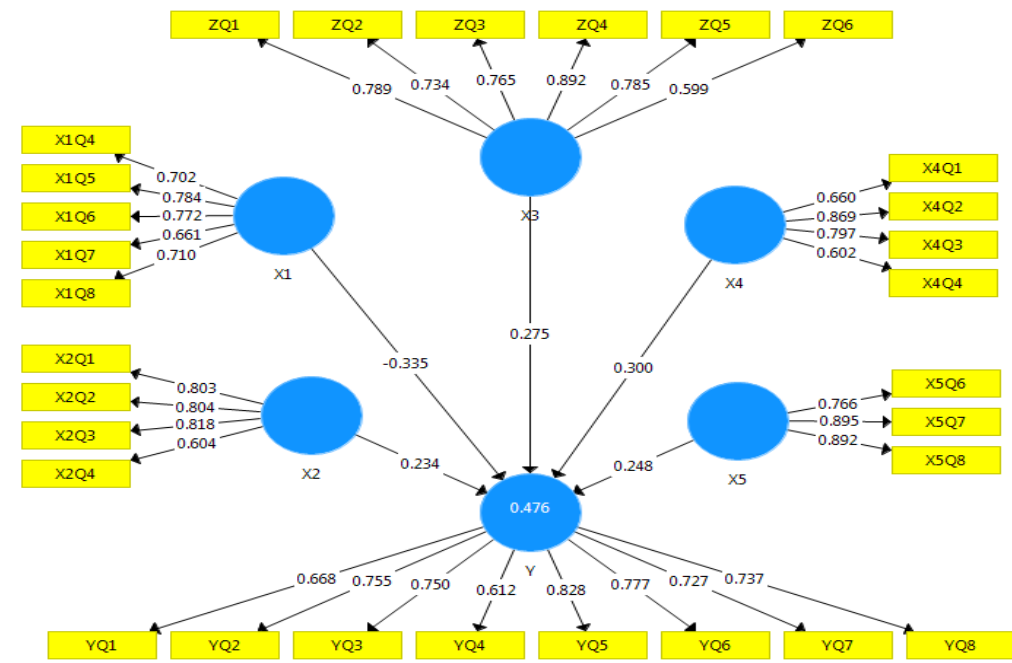

Tabel 4.10

Nilai $R$-square

\begin{tabular}{|c|c|}
\hline Variabel & $\boldsymbol{R}$-square \\
\hline Pengelolaan Keuangan Daerah & 0,476 \\
\hline
\end{tabular}

Sumber: Pengolahan data dengan SmartPLS, 2017

\section{Pengujian Hipotesis}

Tabel 4.11

Result for inner weight

\begin{tabular}{|c|c|c|c|c|c|}
\hline & $\begin{array}{c}\text { Original } \\
\text { Sample } \\
\text { Estimate }\end{array}$ & $\begin{array}{c}\text { Mean of } \\
\text { Subsamples }\end{array}$ & $\begin{array}{c}\text { Standard } \\
\text { Deviation }\end{array}$ & $\begin{array}{c}\text { T- } \\
\text { Statistics }\end{array}$ & P-values \\
\hline X1->Y & $-0,335$ & $-0,331$ & 0,103 & 3,261 & 0,001 \\
\hline X2->Y & 0,234 & 0,272 & 0,102 & 2,285 & 0,023 \\
\hline X3->Y & 0,275 & 0,224 & 0,132 & 2,085 & 0,038 \\
\hline X4->Y & 0,300 & 0,299 & 0,092 & 3,274 & 0,001 \\
\hline X5->Y & 0,248 & 0,265 & 0,091 & 2,718 & 0,007 \\
\hline
\end{tabular}

Sumber: Pengolahan data dengan SmartPLS, 2017

Hasil pengujian dengan bootstrapping dari analisis PLS adalah sebagai berikut:

\subsubsection{Pengaruh Akuntabilitas Keuangan Daerah $\left(X_{1}\right)$ terhadap Pengelolaan Keuangan Daerah (Y)}

Variabel Akuntabilitas Keuangan Daerah memiliki koefisien jalur negatif sebesar-0,335 dan angka signifikansi sebesar 0,001 karena nilai signifikansi lebih kecil dari 0,05 dan nilai koefisien jalur bertanda negatif maka $\mathrm{H}_{1}$ diterima. Sehingga dapat dikatakan bahwa Akuntabilitas Keuangan Daerah memiliki pengaruh negatif dan signifikan terhadap Pengelolaan Keuangan Daerah.

\subsubsection{Pengaruh Value for Money $\left(\mathrm{X}_{2}\right)$ terhadap Pengelolaan Keuangan Daerah $(\mathrm{Y})$}

Variabel Value for Money memiliki koefisien jalur positif sebesar 0,234 dan angka signifikansi sebesar 0,023 karena nilai signifikansi lebih kecil dari 0,05 dan nilai koefisien jalur bertanda positif maka $\mathrm{H}_{1}$ diterima. Sehingga dapat dikatakan bahwa Value for Money memiliki pengaruh positif dan signifikan terhadap Pengelolaan Keuangan Daerah. 
Fredo TSP Hasugian / Jurnal Mutiara Akuntansi Vol. 6, No. 2 (Desember 2021) 175-185

\subsubsection{Pengaruh Kejujuran $\left(\mathrm{X}_{3}\right)$ terhadap Pengelolaan Keuangan Daerah (Y)}

Variabel Kejujuran memiliki koefisien jalur positif sebesar 0,275 dan angka signifikansi sebesar 0,038 karena nilai signifikansi lebih kecil dari 0,05 dan nilai koefisien jalur bertanda positif maka $\mathrm{H}_{1}$ diterima. Sehingga dapat dikatakan bahwa Kejujuran memiliki pengaruh positif dan signifikan terhadap Pengelolaan Keuangan Daerah.

\subsubsection{Pengaruh Transparansi $\left(\mathrm{X}_{4}\right)$ terhadap Pengelolaan Keuangan Daerah $(\mathrm{Y})$.}

Variabel Transparansi memiliki koefisien jalur positif sebesar 0,300 dan angka signifikansi sebesar 0,001 karena nilai signifikansi lebih kecil dari 0,05 dan nilai koefisien jalur bertanda positif maka $\mathrm{H}_{1}$ diterima. Sehingga dapat dikatakan bahwa Transparansi memiliki pengaruh positif dan signifikan terhadap Pengelolaan Keuangan Daerah.

\subsubsection{Pengaruh Pengawasan $\left(\mathrm{X}_{5}\right)$ terhadap Pengelolaan Keuangan Daerah $(\mathrm{Y})$.}

Variabel Pengawasan memiliki koefisien jalur positif sebesar 0,248 dan angka signifikansi sebesar 0,007 karena nilai signifikansi lebih kecil dari 0,05 dan nilai koefisien jalur bertanda positif maka $\mathrm{H}_{1}$ diterima. Sehingga dapat dikatakan bahwa Pengawasan memiliki pengaruh positif dan signifikan terhadap Pengelolaan Keuangan Daerah.

\section{KESIMPULAN DAN SARAN}

\section{Kesimpulan} berikut:

Kesimpulan dari penelitian ini melalui uji statistik SmartPLS 3 adalah sebagai

1. Secara parsial Akuntabilitas Keuangan Daerah berpengaruh secara signifikan terhadap Pengelolaan Keuangan Daerah. Artinya secara terpisah atau parsial variabel Akuntabilitas Keuangan Daerah mempunyai pengaruh terhadap Pengelolaan Keuangan Daerah pada saat pelaksanaan pada tahun 2017.

2. Secara parsial Value for Money berpengaruh secara signifikan terhadap Pengelolaan Keuangan Daerah. Artinya secara terpisah atau parsial variabel Value for Money mempunyai pengaruh terhadap Pengelolaan Keuangan Daerah pada saat pelaksanaan pada tahun 2017.

3. Secara parsial Kejujuran berpengaruh secara signifikan terhadap Pengelolaan Keuangan Daerah. Artinya secara terpisah atau parsial variabel Kejujuran mempunyai pengaruh terhadap Pengelolaan Keuangan Daerah pada saat pelaksanaan pada tahun 2017.

4. Secara parsial Transparansi berpengaruh secara signifikan terhadap Pengelolaan Keuangan Daerah. Artinya secara terpisah atau parsial variabel Transparansi mempunyai pengaruh terhadap Pengelolaan Keuangan Daerah pada saat pelaksanaan pada tahun 2017.

5. Secara parsial Pengawasan berpengaruh secara signifikan terhadap Pengelolaan Keuangan Daerah. Artinya secara terpisah atau parsial variabel Pengawasan mempunyai pengaruh terhadap Pengelolaan Keuangan Daerah pada saat pelaksanaan pada tahun 2017.

\section{Keterbatasan Penelitian}

Penelitian ini memiliki beberapa keterbatasan, antara lain:

1. Metode pengumpulan data menggunakan metode survey melalui kuesioner, kuesioner dibagikan hanya kepada satu lingkup satuan kerja Pemerintah Kabupaten Labuhanbatu Pusat yaitu Satuan Kerja Perangkat Daerah (SKPD), dan Pejabat Pembuat Komitmen (PPK), sehingga hasil penelitian ini tidak dapat digeneralisasi pada lingkup yang lebih luas. 
2. Penelitian ini hanya menggunakan 5 variabel independen (eksogen) yaitu Akuntabilitas Keuangan Daerah $\left(\mathrm{X}_{1}\right)$, Value For Money $\left(\mathrm{X}_{2}\right)$, Kejujuran $\left(\mathrm{X}_{3}\right)$, Transparansi $\left(\mathrm{X}_{4}\right)$ dan Pengawasan $\left(\mathrm{X}_{5}\right)$ dan 1 variabel dependen (endogen) yaitu Pengelolaan Keuangan Daerah (Y) sehingga lingkup penelitian ini sebatas variabel variabel tersebut dan masih dimungkinkan pada penelitian selanjutnya dapat terus digali variabel - variabel lain yang berhubungan dengan pengelolaan keuangan daerah.

\section{Saran}

1. Walaupun secara parsial beberapa variabel memiliki pengaruh positif terhadap pengelolaan keuangan daerah namun dari hasil penelitian diatas variabel akuntabilitas keuangan daerah memiliki pengaruh negatif namun signifikan sebesar 0,001. Oleh karena itu disarankan kepada pemerintah daerah untuk lebih memperkuat faktor akuntabilitas keuangan daerah (kewajiaban pertanggungjawaban) dengan meningkatkan kinerja masa laporan, ketepatan, penyampaian laporan, kesahihan materi laporan serta penyebarluasan isi laporan pada pihak yang berkompeten.

2. Kepada peneliti selanjutnya agar memperluas ruang lingkup penelitian sehingga dapat memberikan kontribusi yang lebih berarti dalam bidang akuntansi pemerintahan. Peneliti selanjutnya juga disarankan untuk mempertimbangkan penggunaan variabel-variabel lain yang lebih luas selain variabel yang diteliti dalam penelitian ini.

\section{DAFTAR PUSTAKA}

Dalimunthe, J., Fadli And Muda, Iskandar., 2014, “ Study on the Impact of Government Complexity and Reguler Governments Size on Human Development Index in North Sumatera, Indonesia”. Global Journal of Management and Business Research: A Administration and Management Vol 14 issue 10

Erlina, Sirojuzilam, Rasdianto 2012. Pengelolaan dan Akuntansi Keuangan Daerah, USU Press, Medan

Fatchurrochman, Agam, 2002. Managemen Keuangan Publik, Materi Pelatihan Anti Korupsi, Indonesian Corruption Watch, Jakarta.

Ghozali Imam, 2008.Structural Equation Modeling. Metode Alternatif dengan Partial Least Square (PLS), Edisi 2, Badan Penerbit Universitas Diponegoro, Semarang.

Halim, 2001. Managemen Keuangan Daerah, Yogyakarta UPP YKPN Instruksi Presiden No. 15 tahun 1983

Jogiyanto,2004. Metodologi Penelitan Bisnis. Salah Kaprah dan Pengalaman Pengalaman, BPFE, Jorjakarta.

Keputusan Presiden (Kepres) No. 74 tahun 2001 tentang tata cara pengawasan penyelenggaraan pemerintah daerah, pasal 1 ayat 6

Mardiasmo, 1999. Akuntansi Sektor Publik. Jakarta. Erlangga.

Muda, Iskandar., Erlina And Bukit, Rina., 2014, “ The Effect of Fiscal Potential Fiscal Needs and Internal Control on the Provincial Intergovernmental Transfer Allocation in the District/ Cities in The North Sumatera - Indonesia". International Journal of Management Sciences and Business Research Vol 3 Issue 10.

----., Rafiki, Ahmad., 2014, “ Human Resources Development and Performance of Government Province of Employees: A Study in North Sumatera, Indonesia".Journal of Economics and Behavioral Studies Vol 6 No. 2, pp 152162

---,And Harahap, Rezeki Martua., 2014, “ Factor Influencing Employees's Performance: A study on the Islamic Banks in Indonesia”.International Journal of Business and Social Science Vol 5 No. 2. 
., Rasdianto And Lubis, Safri Muhammad., 2014, "Implementation of the Cash Revenue System: A case Study in the Local Government Task Forces' Unit of North Sumatera Province, Indonesia”.Information Management and Business Review Vol 6, No. 2, pp 96-108

---------, 2001. Pengawasan, Pengendalian, dan Pemeriksaan Kinerja Pemerintah Daerah dalam Pelaksanaan Otonomi Daerah.

---------, 2002. Otonomi dan Manajemen Keuangan Daerah, Andi, Jogjakarta

Maryono, Warella, Kismartini, 2007. Implementasi Kebijakan Pengelolaan Keuangan Daerah, Provinsi Jawa Tengah.

Mas'Ud Fuad, 2004.Survei Diagnosis Organisasional Konsep dan Aplikasi, Badan Penerbit Universitas Diponegoro, Semarang.

MD Ihyaul Ulum, 2009. Audit Sektor Publik. Bumi Aksara, Jakarta. Mulyana, Budi, 2006, Pengaruh Penyajian Neraca Daerah dan Aksesibilitas Laporan Keuangan Terhadap Transparansi dan Akuntabilitas Pengelolaan Keuangan Daerah Vol.2 No. 1, Mei : hal 65 - 78.

Noordiawan, Putra, Rahmawati, 2007. Akuntansi Pemerintahan. Salemba Empat, Jakarta.

Peraturan Menteri Dalam Negeri No. 13 tahun 2006.Tentang Pedoman Pengelolaan Keuangan Daerah.

Peraturan Pemerintah Republik Indonesia No. 58 Tahun 2005 Tentang Pengelolaan Keuangan Daerah

Renyowijoyo Muindro, 2008. Akuntansi Sektor Publik Organisasi Non Laba, Mitra Wacana Media Jakarta.

Siregar, Liper, 2011. Pengaruh Akuntabilitas Publik dan Pengawasan Terhadap Pengelolaan APBD dengan Standar Akuntansi Pemerintahan sebagai Variabel Moderating pada Pemerintah Kota Pematang Siantar. Tesis, UniversitasSumatera Utara, Medan.

Sopamah, Mardiasmo, 2003. Pengaruh Partisipasi Masyarakat dan Transparansi Kebijakan Publik Terhadap Hubungan Pengetahuan Antara Pengetahuan Dewan Tentang Anggaran Dengan Pengawasan Keuangan Daerah, Simposium Nasional Akuntansi (SNA) VI 16 - 17 Oktober di Surabaya.

Sopanah, Isa Wahyudi, 2007. Pengaruh Akuntabilitas Publik, Partisipasi Masyarakat dan Transparansi Kebijakan Publik Terhadap Hubungan Antara Pengetahuan Anggaran dengan Pengawasan Keuangan Daerah (APBD). Jurnal Akuntansi.

Sulistioni, G., 2003. Fiqh Korupsi : Amanah VS Kekuasaan, Somasi, Nusa Tenggara Barat.

Tuasikal, Askam, 2006. Pengaruh Pengawasan Internal dan Eksternal, Pemahaman Sistem Akuntansi Terhadap Pengelolaan Keuangan Daerah, Serta Implikasinya TerhadapKinerja Unit Satuan Kerja Perangkat Daerah.Disertasi.Universitas Padjajaran Bandung. 